\title{
Project InterActions: A Multigenerational Robotic Learning Environment
}

\author{
Marina U. Bers
}

Published online: 13 October 2007

(C) Springer Science+Business Media, LLC 2007

\begin{abstract}
This paper presents Project InterActions, a series of 5-week workshops in which very young learners (4- to 7-year-old children) and their parents come together to build and program a personally meaningful robotic project in the context of a multigenerational robotics-based community of practice. The goal of these family workshops is to teach both parents and children about the mechanical and programming aspects involved in robotics, as well as to initiate them in a learning trajectory with and about technology. Results from this project address different ways in which parents and children learn together and provide insights into how to develop educational interventions that would educate parents, as well as children, in new domains of knowledge and skills such as robotics and new technologies.
\end{abstract}

Keywords Early childhood education - Robotics ·

Programming $\cdot$ Constructionism

\section{Introduction}

Our robot is a violinist who plays "Ode to Joy" on violin. I chose this because we have had music in our family for all the generations we know about. I picked the violinist because all three of my sisters play the violin. I really like the violin...We built it using Lego and Robolab. We programmed it on our old Pentium 1 computer. We did about $3 / 4$ of the work at home. The hardest part was making the gears

M. U. Bers $(\square)$

Tufts University, 105 College Ave., Medford, MA 02155, USA

e-mail: Marina.bers@tufts.edu work so that the bow went back and forth over the violin. I learned that robots can do a lot more than I thought. I really had fun.

Jack (7 Years Old) and His Dad

While in previous decades robots have captured the imagination of children through popular movies such as Star Wars, nowadays they can be found in houses and cities. Robots help with simple tasks such as vacuum cleaning and grass cutting; they can perform autonomous or preprogrammed tasks that are dangerous or difficult for humans, such as radioactive waste clean-up and surgical procedures; or they can automate mindless but precise repetitive tasks, such as those involved in automobile procedures.

As robots become more ubiquitous in our everyday lives, the use of educational robotic kits is becoming a popular means to provide children with opportunities to learn how to make their own robots (Resnick 1998). Many colleges today have a long lasting tradition of engaging students in robotic challenges and competitions-events where robots have to accomplish a given task (usually to out perform another robot), an example of which is the Massachusetts Institute of Technology's robot design contest. However, robotics competitions for pre-high school and high-school are becoming more prevalent; perhaps most notable are the FIRST (For Inspiration and Recognition of Science and Technology) LEGO League competition (pre-high school) and the FIRST Robotics Competition, a national robotic competition in which high school students team up with professional engineers, amongst many others. Liberal arts colleges have implemented different versions of a pioneering course called "Robotic Design Studio", where students learn engineering principles by designing and implementing kinetic 
sculptures and final open-ended projects that integrate artistic expressions with robotic artifacts (Turbak and Berg 2002).

Many books have been published about how to use robotics as an introduction to the powerful ideas of engineering, most of them focusing on older students (Martin 2001) and some on young children and their teachers (Bers 2007a,b). Researchers have also developed extensive curriculum ranging from building a sturdy chair for Mr. Bear, which gets children to focus on basic engineering design principles, to creating a transportation system that requires working with gear ratios and friction (Rogers and Portsmore 2004). In the process, students of all ages develop knowledge about engineering and programming and learn how to apply physics and mathematics to solve real-world problems associated with the making of the robotic artifacts.

While most of this work is done in high schools, middle and upper elementary schools (Rogers and Portsmore 2001), recent work also started to look at the use of robotics in early childhood, grades preK-2 (Bers in press; Bers et al. 2002; Cejka et al. 2006). We live in an advantageous time for introducing technology in early childhood. Given the increasing mandate to make early childhood programs more academically challenging, ${ }^{1}$ the use of robotics can provide a playful bridge to integrate academic demands in math, science and technology with personally meaningful projects, which are at the core of successful and developmentally appropriate early childhood programs (Bredekamp and Copple 1997).

The recent report, Technically Speaking: Why All Americans Need to Know More About Technology (Pearson and Young 2002), explains why all citizens need to become "stewards of technological change." The report summarizes research showing that children and adults know shockingly little about technology and engineering and makes a series of recommendations for addressing the need for increased technological literacy. Although the report does not describe how to carry out this recommendation, it does note that "developing technological literacy will require early and regular contact with technology in the school setting" (Pearson and Young 2002, p. 53).

Robotics provides opportunities for young children to learn about sensors, motors, and the digital domain in a playful way by building their own projects such as cars that follow a light, elevators that work with touch sensors, and puppets that can play music. Young children can become engineers by playing with gears, levers, joints, motors, sensors, and programming loops, as well as storytellers by creating their own projects that move in response to their

\footnotetext{
${ }^{1}$ As of 2006, 37 states have included engineering/technology standards in their educational frameworks.
}

environment (Bers in press). Robotics can also be a gateway for children to learn about applied mathematical concepts, the scientific method of inquiry, and problem solving.

By extending the potential of traditional educational manipulatives-a tradition started when Fröebel invented kindergarten in the 1800s and introduced a series of gifts to teach children about size, number and shape-robotics also engages young children in using their hands and developing fine motors skills as well as hand-eye coordination. Robotic manipulatives also invite children to participate in social interactions and negotiations while playing to learn, and learning to play (Resnick 2003). Learning how to function in the social world is an important developmental task that young children need to accomplish. Early childhood teachers are more likely to welcome the use of these innovative technologies if they can serve this purpose as well and not only engage cognitive aspects of learning.

Despite all of the potential benefits of robotics in education, research has shown the difficulties of introducing new technologies in schools (Cuban 2001). Most of the obstacles are not due to the limitations of the technology, the children, or the teachers, but rather because of the logistical challenges of working in short-blocks of time with one teacher per 20 or more children (Rogers and Portsmore 2004; Erwin and Rogers 2000). The challenges of introducing technology in early childhood education are even greater. On the one hand, teachers are not wellprepared to understand the possibilities of new technologies and, although state and federal curriculum frameworks mandate the study of technology and engineering, teachers tend to shy away from these domains. On the other hand, many early childhood teachers have questions regarding the developmental appropriateness of introducing technology and engineering in the early grades.

Most early childhood teachers were trained in a Piagetian tradition of developmental stages that suggests that children enter the concrete operational stage at age six or seven. Thus, according to Piaget, only at this age, a child gains the ability to perform mental operations in her head and also to reverse those operations. As a result, a concrete operational child has a more sophisticated understanding of number, can imagine the world from perspectives other than her own, can systematically compare, sort, and classify objects, and can understand notions of time and causality (Piaget 1971). Based on this developmental model, early childhood teachers, who work with children younger than 7 years old, tend to make the argument that a child's ability to program might be predicted by his or her general developmental level and, by extension, a preoperational kindergartener, typically 5 years old, may be too young to benefit from or understand computer programming and engineering design. 
However, since its introduction, various problems and inconsistencies have been identified with Piaget's stage model (Turkle and Papert 1992). For example, studies have shown that when a task and its context are made clear to children, they exhibit logical thought and understanding well before the ages that Piaget had suggested as a lower limit (Richardson 1998).

Although young children might be developmentally capable of understanding basic programming concepts and building strategies involved in robotics, most early childhood programs can not provide them with the in-class adult support needed to have succesful robotic-based programs. On the one hand, while young children might understand the concept of a sequence of steps or the looping involved in programming, they might not have the fine motor skills needed to manipulate the mouse and use iconic-based programming languages or the reading and writing skills to use syntax-based programming languages. On the other hand, the lack of early childhood teacher training in these domains makes teachers feel insecure and uncornfortable introducing a technology they do not understand well themselves.

In order to address these problems, the most obvious approach is to better prepare early childhood teachers in the use of robotics (Bers and Portsmore 2005; Bers et al. 2002). Complimentary to this approach is the possiblity of utilizing the parental resources that are available in the community to suppport the work of the teachers as there is a well-established tradition of welcoming parents into the early childhood classrooms. However, although in principle this is a good idea, bringing parents into classrooms to volunteer at snack time or to read a story to the children (a skill that most parents have) is much different than asking them to help with building robots and programming their behaviors.

The research on Project InterActions presented in this paper explores this challenge by bringing together parents and young children, 4-7 years old, in a robotic learning environment. How do parents and children learn and work together? How can parents best support children's learning, while developing and furthering their own technical knowledge? How to set up a learning environment as a multigenerational community of practice? Project InterActions's research was done in the context of weekend workshops, instead of classroom settings, to study the particularities of parents and children working together without the pedagogical supervision of teachers. Informal learning environments, such as these family weekend workshops, provide a naturalistic laboratory to learn what issues need to be taken in consideration when bringing parents into the classroom to support early childhood programs that want to introduce technology, in particular, robotics.
Involving parents in the academic education of their children is not a new practice in early childhood education. For example, research on home-school connection has shown that parental involvement plays an important role in developing students' skills and attitudes towards school and hence in ensuring educational success (Hess and McGarrey 1987). While this practice is widespread in literacy, where research has shown that the practice of parents reading with their young children is a significant contributor to young children's learning to read (Teale 1984; Jordan et al. 2000; Senechal and LeFevre 2002), it is only starting to emerge in the field of technology education. Because of its recent inception, there is no available longitudinal data but rather anecdotal examples of successful interventions (Wright and Church 1986). Extending this work, the goal of Project InterActions is to explore the challenges and opportunities of conducting multigenerational learning experiences that promote not only parental involvement but also parental learning in the area of robotics technology.

More specifically, this paper reports on three different dimensions of Project InterActions that can inform future work: (1) The learning environment (How were the family workshops set-up and developed as a multi-generational community of practice that follows a constructionist pedagogy of teaching and learning?), (2) The learners (What were the gender, skills and backgrounds of the parents and children who chose to participate in this project, and in which ways they did they chose to participate?), and (3) The learning outcomes (Were parents and young children working together able to learn both engineering design and building, and programming aspects of robotics?). In the next sections I will address each of these dimensions.

First, I will introduce Project InterActions by highlighting the research questions that I am addressing in this paper, as derived from the three dimensions presented above. Second, I will provide the theoretical background that informs each of the three dimensions. Third, I will describe both the research and teaching methods. Fourth, I will organize the results sections around the same three dimensions that originated the research questions: the learning environment, the learners, and the learning outcomes. Finally, I will conclude with a discussion of lessons learned from Project InterActions that can inform the work with parents supporting robotic programs in both formal and informal early childhood learning environments.

\section{Project InterActions}

Project InterActions looks at the many interactions that exist when parents and young children, 4-7 years old, 
come together to program and build a robotic project that is meaningful for the families (Bers et al. 2004). As part of the study, we conducted a series of six different family workshops that met for two and a half hours during the weekend for a period of 5 weeks. The goals of the family workshops were (1) to explore how to develop a learning environment that would nurture the formation of a multigenerational community of practice, (2) to understand what kind of families chose to participate in these workshops and what kinds of pedagogical devices needed to be in place to promote both parents and children's learning, and (3) to evaluate results of their participation in the workshops, such as parents and children's learning experiences.

Project InterActions originated from a previous study done in a Jewish day school in Buenos Aires, Argentina, in which families made robotic creative prayers and shared them with members of the community at the synagogue before the traditional prayers of the Jewish High Holidays (Bers and Urrea 2000). While this first study showed that young children could learn about both robotics and religious traditions while working together with their parents in the creation of interactive robotic projects, Project InterActions was designed to explore further some of these ideas by focusing on the following research questions associated with the three dimensions presented earlier:

(1) Learning environment: Is the context of a constructionist community of practice, such as the family workshops in Project InterActions, an appropriate pedagogical approach for supporting multigenerational learning? How do we develop a robotics curriculum aligned with statewide technology curriculum frameworks that engages learners in personal discovery and the creation of personally meaningful robotic projects?

(2) Learners: Who chooses to participate, and in which ways, in these family workshops? How is the learning experience similar or different for parents and children? What are the complexities of developing an educational intervention that involves both parents and very young children learning something new together?

(3) Learning outcomes: Are parents and children working together able to learn about robotics? Are young children developmentally capable of learning both mechanical and programming aspects of robotics? What is considered learning by parents and children (e.g. differentiated levels of participation in the community of practice)?

The following sections address each of these three dimensions while providing theoretical background to understand the constructs upon which the study was designed: communities of practice, constructionist learning, and legitimate peripheral participation.

\section{Learning Environment: Project InterActions as a Constructionist Community of Practice}

In a constructionist community of practice, people learn by doing, not by being taught. They learn by engaging in the different practices of the community and they learn by increasing their level of participation in the community's practices as they gain new knowledge and develop new skills (Lave and Wenger 1991).

Project InterActions workshops are set up as constructionist communities of practice. The constructionist philosophy was developed by Papert (1980), building upon the work of Piaget. Papert describes constructionism as "built on the assumption that children will do best by finding ('fishing') for themselves the specific knowledge that they need," and he adds, "The kind of knowledge that children most need is the knowledge that will help them get more knowledge" (Papert 1993, p. 139). Papert envisions computers and new technologies, such as robotics, as wonderful tools to enable learners to learn by engaging in the design of personally meaningful projects. These "concrete" products can be displayed and shown to others, and thus "constructions in the world" support "constructions in the mind." Project InterActions workshops are designed as a learning environment that not only supports learning by doing through active inquiry, but also learning by participating in a community of practice that shares the "constructions in the world".

As defined by Lave and Wenger (1991) the concept of communities of practice involves knowledge and skills, as well as a set of relations between people and ideas. A community of practice requires mutual engagement of participants, a joint enterprise that produces relations of accountability and negotiation, and a shared repertoire that includes routines, words, concepts, stories, ways of doing things, etc., which the community has produced or adopted in the course of its existence. Learning environments such as workshops that last several weeks are natural spaces for forming communities of practice in which people engage with each other and with new knowledge and skills by producing artifacts, relationships and ideas.

Project InterActions' workshops are designed to nurture the formation of a multigenerational community that engages in the practice of making robotic projects to learn both mechanical and programming aspects of robotics. What are the characteristics of Project InterActions' family workshops? Why apply the framework of communities of practice $(\mathrm{CoP})$ to develop these learning environments?

In terms of the pedagogical approach, it was decided to use the CoP model to craft the learning environment because it provides a useful framework to understand learning as situated in a social context beyond the traditional school setting (Rogoff 1994; Rogoff et al. 2001). The 
social context of Project InterActions is the family. Families are natural communities of practice, but they are not always communities of practice focused on learning something new. Although all family members learn many things just by belonging to a family structure and by participating in the family's rituals and practice, "learning something new" is not the defining characteristic of a family.

Project InterActions provided opportunities for family members to become part of a community of practice focused on learning robotics technology by engaging in a concrete practice: the creation of a robotic artifact with shared meaning and the participation in that experience with other families. Each family brought into their practice their own historical and social context (i.e. particular dynamics in the parent/child relationship that are a reflection of the family structure but also of the cultural context, rituals and values of each family). This context shaped the way in which each family approached their practice together and also the way in which families interacted with each other.

In Project InterActions families were doing many different activities while participating in a constructionist learning environment, in which the technology was used as a material to create personally meaningful projects (Papert 1991; Kafai and Resnick 1996). They (a) learned both programming and engineering aspects of robotics, (b) engaged in the design process (i.e. coming up with a project idea, developing the concept in their design journals and implementing it), (c) explored things they cared about to develop a project idea, (d) engaged in conversations that they might not have had otherwise both at home and during the workshops, (e) wrote design journals, (f) created project websites, and $(\mathrm{g})$ participated in unstructured interactions and technology circles in which participants shared their successes, failures and questions at least twice a day (Bers 2004; Bers et al. 2004; Beals and Bers 2006).

In sum, the notion of CoP provided a theoretical foundation to design the workshops as learning environment where both parents and children had opportunities to participate in the development of knowledge and skills about robotics, as well as in developing positive attitudes to learn with and about technology. However, developmentally speaking, how can a learning environment provide opportunities for practice for both adults and children? The next section addresses the concept of legitimate peripheral participation, which sheds light over this question.

\section{Learners: Conferring Legitimate Peripheral Participation}

Based on the work of Lave and Wenger (1991), one of the salient characteristics of $\mathrm{CoP}$ is that they legitimize different ways for people to participate in the learning experience. As opposed to traditional classroom settings in which all learners need to acquire the same knowledge at the same time because it will be tested, CoP offers a model for differentiated levels of participation, in a central or a peripheral way, as a novice or expert, as a newcomer or old-timer. For example, in Project InterActions, young children were not expected to attain full participation, but were granted the legitimacy to participate as peripheral members and achieve readiness instead of mastery.

Legitimizing learning as participation in a community of practice happens often at home. For example, even if young children do not have proper table manners, they are still granted legitimate peripheral participation and are allowed to sit at the table and participate in the dinner rituals as a stepping stone towards growing into civilized meal participants. The goal of Project InterActions workshops was to provide a similar context to the family meala space in which young children would be granted the legitimacy to explore certain aspects of programming and building while, at the same time, being immersed in a learning environment in which making robots and talking about technical questions and approaches for problemsolving were part of the everyday practice.

Legitimate peripheral participation is a process by which newcomers become included in a community of practice. Project InterActions's workshops are designed to accommodate all sorts of newcomers: newcomers to the world of technology, newcomers to a constructionist style of teaching and learning, newcomers to working together with family members. This richness allows for a flexible community in which there are not fixed roles. Since most participants are newcomers in at least one aspect of the workshop (e.g., some parents do not know how to work with their children, some children do not know how to use the mouse or keyboard) workshop facilitators make sure to make explicit the fact that newcomers are granted legitimacy in this CoP.

In Project InterActions, as in other communities of practice, "the issue of conferring legitimacy is more important than providing teaching" (Lave and Wenger 1991, p. 92). However, the means to confer legitimacy must be designed in the learning environment. In the workshops, legitimate access was secured for both parents and children by using a simple language and by assuring them that the goals of the workshops were to have fun together, learn together, and work together in a robotic project about something they cared about. Based on previous experience, in which some parents became competitive with each other (Bers et al. 2004; Beals and Bers 2006), we knew that to legitimize peripheral participation we needed to set up an environment in which the learning process mattered more than product, and in which 
verbal discourse (mostly used by the parents in the workshops) and playful imitation (mostly used by the children), were both granted legitimacy as ways of learning.

In sum, in a community of practice composed by different kinds of newcomers and learners with different developmental possibilities, it is important to design means for conferring legitimate peripheral participation and for helping newcomers move into more central roles. How do we evaluate learning outcomes in such a community of practice? How do we understand what learning means for the different participants? The next section addresses these issues.

\section{Learning Outcomes as Levels of Participation in a Constructionist Environment}

The notion of communities of practice shifts the question from "what are the learning outcomes?" to "what kind of levels of participation learners attain?" (Wenger 1998). The goal of Project InterActions is to create a learning environment in which learners can participate in a CoP that engages them in making robotic projects. Success is measured by differentiated levels in knowledge about robotics before and after participating in Project InterActions' workshops.

In communities of practice the curriculum unfolds as opportunities for practice emerge (Lave and Wenger 1991). However, when the goal is to promote learning about robotics, a teaching curriculum that focuses on powerful ideas or content knowledge from the fields of mechanics, electronics, and computer programming is also needed. In Project InterActions' workshops, the teaching curriculum introduced basic skills and knowledge about robotics that aligned with the state frameworks on technology for the early grades in Massachusetts.

\section{Research Methods}

In terms of methods, Project InterActions used the research methodology of design experiments. Design experiments provide a method for conducting educational research with the goal of improving learning and not just of describing it (Collins 1992; Brown 1992; Barab and Squire 2004; Bell 2004; Fishman et al. 2004; DiSessa and Cobb 2004). Thus, researchers become practitioners by designing research studies that are also interventions.

The notion of "design experiments" or "design-based research", pioneered by Collins (1992) and Brown (1992), to engineer innovative learning environments and simultaneously study how those interventions impact learning, brought to the field of education research an important methodological contribution. Design experiments provide an approach for conducting iterative studies in complex learning environments. Due to their interventionist method, design experiments are particularly helpful when exploring how a technological innovation affects learning and educational practice (diSessa et al. 1991) and can serve as a model or test-bed for broader educational reform.

According to Cobb et al. (2003) design experiments have both a pragmatic bent_- "engineering" particular forms of learning - and theoretical orientation-developing domain specific theories by systematically studying those forms of learning and the means of supporting them. Project InterActions" workshops were "engineered" as a multigenerational CoP.

To date, six different design experiments over a period of 3 years were conducted as part of Project InterActions (see Fig. 1). The first two were pilot studies, exploratory experiments with small number of participants aimed at better developing the curriculum, identifying the elements needed to nurture the $\mathrm{CoP}$, and forming a long-lasting research and teaching team. The other four studies were designed to investigate how learning happened, and for whom, in the workshops. Parents could choose to be copresent with their children during the workshops or to work with them from home. Thus of the four studies, two had copresent parents and the other two had child-only workshops. A total of 132 learners participated in these design experiments, including the pilot projects.

Based on experience gathered in the two pilot projects, the curriculum, teaching and data collection methods were revised and four different workshops were conducted. In two of the workshops parents could choose to come in with their children; in the other two parents could work from home and children attend the workshops on their own.

\section{Teaching Methods}

The six studies in Project InterActions were set up in similar ways. Each study consisted of a workshop of five

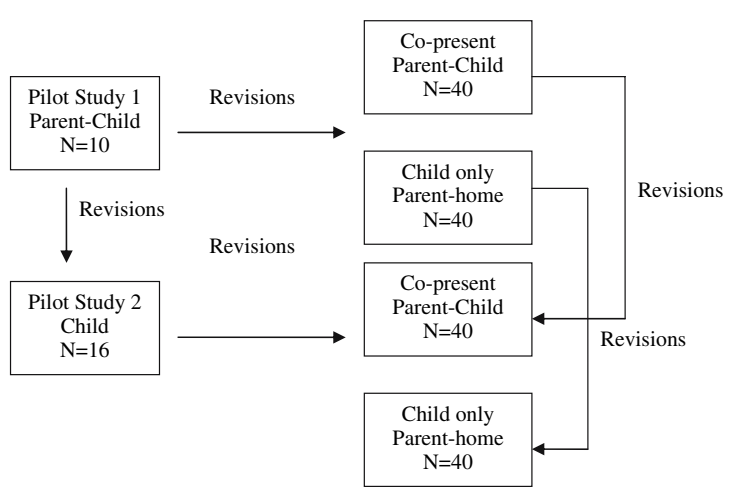

Fig. 1 The iterative series of workshops as a design experiment 
sessions of two and a half hours each. During the first two sessions of the workshop, participants were taught the basics of the robotics technology. Participants received handouts and proposed activities to do at home in between sessions. Some of those activities were designed for families to develop more advanced skills and concepts. During the next two sessions, learners created a final project. Art materials were provided so they could be incorporated into final projects. During the last day, participants shared their projects with each other and invited guests, and documented them on the Project InterActions website ${ }^{2}$. Over the course of the workshops, the children and families took home a robotics kit, supporting materials, and a design journal with time-tracking sheets, so families could report their activities at home. A tech support hot-line was available to families during the duration of the study.

During the workshops we used the LEGO $^{\circledR}$ MINDSTORMS $^{\circledR}$ robotics kit and the ROBOLAB ${ }^{\text {TM }}$ programming language. The kit contains a large LEGO ${ }^{\circledR}$ brick with an embedded micro-computer, called the RCX or programmable brick, an infrared tower that connects the programmable brick to the computer, so the programs children create in the computer can be downloaded to the programmable brick, and a variety of LEGO ${ }^{\circledR}$ pieces in different sizes and shapes. Some of the pieces are familiar, such as beams, bricks, and plates. Others are unique to robotics such as motors, light sensors, touch sensors, wires, axles, and gears. The ROBOLAB ${ }^{\mathrm{TM}}$ programming language provides a drag-and-drop iconic interface that makes programming easy (it is possible to program without knowing how to read and write). Both MINDSTORMS ${ }^{\circledR}$ and ROBOLAB $^{\mathrm{TM}}$ have a long trajectory of being used in robotics-based educational studies both in the US and abroad (Rogers and Portsmore 2004).

Project InterActions' curriculum is organized around two different kinds of powerful ideas: domain specific (i.e., robotic concepts and skills), and ideas across domains (i.e., problem solving or debugging) (see Table 1) (Papert 1991). The curriculum also takes into consideration the different developmental stages of the family members. While choosing the powerful ideas to include in the curriculum, emphasis was put in meeting the Massachusetts Technology and Engineering frameworks. We were particularly interested in observing if some of these concepts, which the frameworks identify for upper elementary grades, could be introduced to younger children in the context of a CoP and with the aide of robotic technologies.

Using these powerful ideas as guiding principles, a teaching curriculum was developed with two interconnected sets of lesson plans: one for completing while in the workshop, and another for working at home (see Table 2).

\footnotetext{
$\overline{2 \mathrm{http}: / / w w w}$.ase.tufts.edu/devtech/Project_Inter-Actions/
}

To support the work at home, each family received a resource book especially developed for Project InterActions, including an introduction to LEGO engineering and to programming with the ROBOLAB iconic language (Portsmore 1999). The language is simple and the text is supported with graphical images. Throughout the book, Mr. Lego-Head introduces the learners to different concepts, useful information, hints to make the work easier, mini-challenges, and reminders of things to do so the work progresses smoothly (for example, saving the program). Additionally, for each lesson plan, there is advanced information for the adult.

\section{Pilot Studies}

The first pilot workshop was conducted with 10 families. Each family worked a minimum of twelve and a half hours with robotics (Bers et al. 2004; Bers 2004). Although it was not mandatory for families to take the kit home, some chose to do it. These families had a better learning experience and so in the next studies we requested that families take the kits home and to provide the needed out-of-workshop support. In this first pilot study, families created final projects such as the "Easter Bunny", "Go-Lem, A Matzah-Seeking Robot", and a birthday cake that sings an Armenian song while flashing lights as candles. Based on this experience, the curriculum, as well as the research methodology and the data collection methods, were modified.

A second pilot study was conducted with 16 children in a local early childhood lab school. Their parents participated by supporting their children's work from home during the 8-week-long curriculum unit (Staszowsky and Bers 2005; Kahn and Bers 2005). The curriculum culminated by children making a final robotic project representing an aspect of their cultural heritage. For example, children created a flashing Christmas tree (see Fig. 2), a manger for Jesus with a hovering moving angel, and a hopping Eskimo that runs away from a polar bear. Both parents and children $(n=32)$ completed pre- and post-questionnaires. Results from this experience informed the further modification of the curriculum and the clarification of research questions.

Based on the experience of the two pilot studies, four design experiments were conducted with a total of 80 participants: two studies in which children came to the workshop with their parents and two studies in which children came to the workshop on their own and parents were expected to support and collaborate with their children's projects at home. Since the studies were done in a naturalistic environment, the attendance decision was made by participants who chose to sign up for one or the other group, based on their family situation. 
Table 1 The curriculum and the MA technology/engineering frameworks

\begin{tabular}{|c|c|c|}
\hline Powerful ideas & Definition & MA curriculum technology/engineering frameworks \\
\hline Problem solving & Inventing a solution to a given problem & General design Process \\
\hline Brainstorming & To utilize creativity during problem solving & $\begin{array}{l}\text { Demonstrate methods of representing solutions to a } \\
\text { design problem }\end{array}$ \\
\hline Design process & $\begin{array}{l}\text { A sequence of steps that leads one through a problem } \\
\text { solving challenge }\end{array}$ & $\begin{array}{l}\text { Identify and explain steps of engineering design } \\
\text { process }\end{array}$ \\
\hline $\begin{array}{l}\text { Robotic autonomy } \\
\text { versus remotely operated }\end{array}$ & $\begin{array}{l}\text { The difference between an object that can operate itself } \\
\text { by following programmed instructions and one that } \\
\text { requires input from a source other than itself in order } \\
\text { to operate }\end{array}$ & $\begin{array}{l}\text { Identify and explain how symbols are used to } \\
\text { communicate a message }\end{array}$ \\
\hline Programming sequence & $\begin{array}{l}\text { The specific order in which commands are arranged to } \\
\text { ultimately perform a task }\end{array}$ & $\begin{array}{l}\text { Identify and explain how symbols are used to } \\
\text { communicate a message }\end{array}$ \\
\hline Identify constraints & To recognize the limitations of a given problem & $\begin{array}{l}\text { Explain how design features would affect } \\
\text { construction of a prototype }\end{array}$ \\
\hline Prototyping & $\begin{array}{l}\text { To construct a model of the proposed solution to a } \\
\text { problem for testing }\end{array}$ & $\begin{array}{l}\text { Describe and explain the purpose of a given } \\
\text { prototype }\end{array}$ \\
\hline Material selection & $\begin{array}{l}\text { To identify the most appropriate materials to create a } \\
\text { solution }\end{array}$ & $\begin{array}{l}\text { Identify materials used to accomplish a design task } \\
\text { based on a specific property }\end{array}$ \\
\hline Energy transfer & To change one form of energy into another & $\begin{array}{l}\text { Describe how humans use parts of the body as tools, } \\
\text { and compare that with animals }\end{array}$ \\
\hline Forces & A push or pull that acts on an object & $\begin{array}{l}\text { Identify relevant design features for building a } \\
\text { prototype }\end{array}$ \\
\hline Motion & $\begin{array}{l}\text { A change of position of one body with respect to } \\
\text { another body, frame of reference, or a coordinate } \\
\text { system }\end{array}$ & $\begin{array}{l}\text { Compare natural systems with mechanical systems } \\
\text { that are designed to serve similar purposes }\end{array}$ \\
\hline Wheel and axle & $\begin{array}{l}\text { A simple machine consisting of a rotating rod placed in } \\
\text { the wheel's center, thus making it easier to move } \\
\text { objects }\end{array}$ & $\begin{array}{l}\text { Identify tools and simple machines used for a } \\
\text { specific purpose }\end{array}$ \\
\hline Lever & $\begin{array}{l}\text { A simple machine consisting of an arm pivoting at a } \\
\text { center point to easily lift objects }\end{array}$ & $\begin{array}{l}\text { Identify tools and simple machines used for a } \\
\text { specific purpose }\end{array}$ \\
\hline Gear & A wheel with teeth used to transfer motion & $\begin{array}{l}\text { Identify and explain the difference between simple } \\
\text { and complex machines }\end{array}$ \\
\hline Friction & $\begin{array}{l}\text { The force that opposes a desired motion due to the } \\
\text { contact of objects }\end{array}$ & $\begin{array}{l}\text { Explain how design features would affect } \\
\text { construction of a prototype }\end{array}$ \\
\hline Stability & The necessary property of structures to prevent failure & Identify relevant design features of a solution \\
\hline Sensors & $\begin{array}{l}\text { Objects that identify a change in immediate surrounding } \\
\text { environment }\end{array}$ & $\begin{array}{l}\text { Describe how humans use body parts as tools, and } \\
\text { compare that with animals }\end{array}$ \\
\hline Feedback & $\begin{array}{l}\text { The response of sensors to a change in the surrounding } \\
\text { environment }\end{array}$ & $\begin{array}{l}\text { Identify the five elements of a universal system } \\
\text { model }\end{array}$ \\
\hline Looping & $\begin{array}{l}\text { A program method used to create an infinite program so } \\
\text { that tasks may be repeated }\end{array}$ & $\begin{array}{l}\text { Identify and explain how symbols are used to } \\
\text { communicate a message }\end{array}$ \\
\hline Input and output & $\begin{array}{l}\text { The terms used for information exchanged through a } \\
\text { computer }\end{array}$ & $\begin{array}{l}\text { Identify the five elements of a universal system } \\
\text { model }\end{array}$ \\
\hline Debugging & To identify the error(s) in a computer program & $\begin{array}{l}\text { Identify and explain the steps of the engineering } \\
\text { design process }\end{array}$ \\
\hline
\end{tabular}

\section{Data Collection}

The use of the design experiments research method involves making a series of design iterations to observe and adjust parameters. Thus, it is important for researchers to generate a comprehensive record of the ongoing design process. It is standard procedure in most engineering disciplines to keep records to support the retrospective analysis of the experiment (Edelson 2002). Accordingly, the Project InterActions team of 12 members led by the author and composed of graduate and undergraduate students in the DevTech research group and staff at the Center for Educational Engineering Outreach at Tufts University, used several ways for keeping records. It is important to note that the team received training on practical aspects of teaching family workshops, as well as on the theoretical 


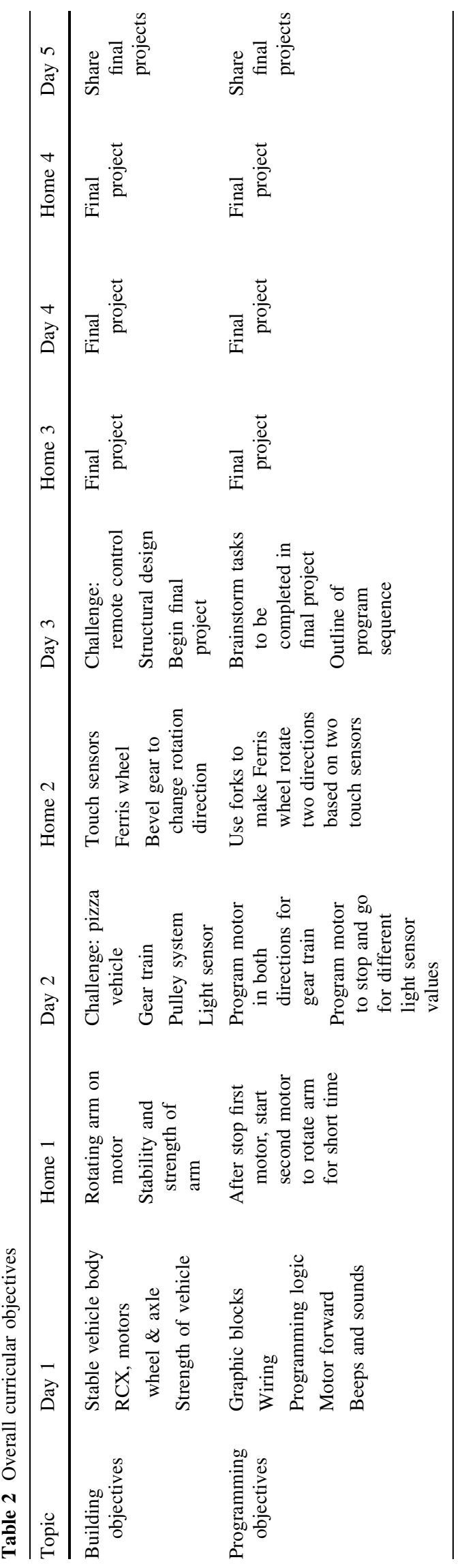

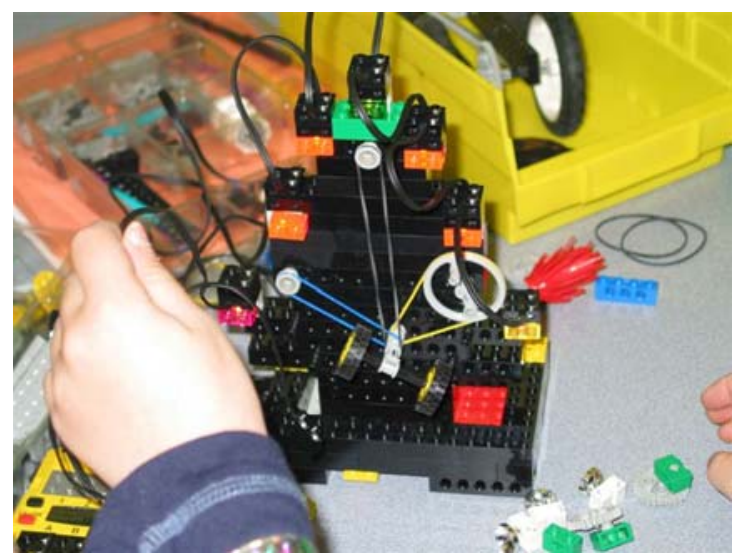

Fig. 2 A Christmas tree made out of Lego and blinking lights

questions involved in the research, such as "What are the different approaches taken by adults and children to learn robotics and programming?"

(1) Design journals: Each participant was provided with a design journal with a guided worksheet to record their work at home and with open pages to sketch out their ideas. Design journals were collected at the end of the workshop.

(2) Websites: At the end of the workshop each child or parent/child dyad created a final project website. They were requested to include a recount of their learning experience by focusing on what was hard and what was easy, a description and pictures of their projects, and overall reflections.

(3) Final project: Videotaping and still pictures of the process of developing the final projects was done throughout.

(4) Open-ended observation notes by facilitators: Each facilitator was in charge of recording interactions and observations of assigned workshop participants. Facilitators were asked to pay particular attention to behaviors or conversations that might provide information regarding the three research dimensions mentioned earlier: the learning environment, the learners themselves and the learning outcomes.

(5) Guided observations by research staff: Research staff was provided with a check list to elicit their perceptions on both parents and children's experiences while participating in the workshops.

(6) Videotapes of interviews with participants: The videotaping of interviews with participants was done in a casual, open-ended, non-invasive manner. However, it followed a specific protocol to facilitate replicability between design experiments.

(7) Programming and building skills self-assessment: This instrument was used to evaluate if participation in the workshop had an effect in participant's perceptions 
regarding their own learning about both programming and building aspects of robotics. It was administered orally to the young children and in writing to the parents before and after the workshop. It includes:

(a) Three statements about learner's ability to build with LEGO robotics, such as "I can use Legos to build the things that I want to make", "I know how to make a robot that moves", and "I can learn how to make a robot".

(b) Three statements about learner's ability to program, such as "I know how to program a computer", "When something goes wrong when I'm using the computer, I can try different ways to ure out how to fix it on my own", and "I can learn how to use a new program on the computer."

(c) Two statements about attitudes towards computers "Learning new things about computers and other machines is easy for me" and "I am able to make things on the computer that show what is special or important about me".

Parents and children responded to each item using a 5point likert scale with a response of 5 indicating "No way" (strongly disagree) and a response of 1 indicating "Definitely!" (strongly agree). This self assessment instrument was adapted from DeLuca (2003).

(8) Positive Technological Development (PTD) questionnaire: This questionnaire examines how learners in technology-rich contexts develop six different assets: competence, confidence, connection, character, caring, and contribution (Bers 2006). It uses a Likert-like scale to assess whether learners agree to certain descriptions about their attitudes and experiences in technology-related activities and contexts. For example, in regard to caring, a description may state, "It is important for me to teach others the things that I already know about computers." In the following study, only the subscales of competence and confidence were used. These were adapted and shorten from the generic PTD version (Bers 2007a , b) to accommodate the developmental level of the young children. A preliminary study analyzing reports using the adapted PTD instrument was done by Chau and Bers (2006). Inspired by the work of applied developmental science on positive youth development (Lerner et al. 2005), PTD defines the competence construct as "the ability to use technology, to create or design projects using the computer in order to accomplish a goal, and to debug projects and problemsolve". The confidence construct is defined as "a sense of oneself as someone who can act and learn to act successfully in a technology-rich environment and find help when necessary." The definitions of both competence and competence, and the development of the PTD's subscales, were based on the concept of technological fluency introduced by Papert (1980) in referring to the ability to use and apply technology in a fluent way, effortlessly and smoothly, as one does with language. PTD involves not only mastering technological skills and concepts, but also the ability to learn new ways of using computers in a creative and personally meaningful way (Committee on Information Technology Literacy 1999). Items were adapted from the computer-user self-efficacy scale developed by Cassidy and Eachus (2002) and the Computer Attitude Questionnaire developed by the Texas Center for Educational Technology. The PTD competence subscale used in this study includes six items for adults and three for children. The confidence subscale includes five items for adults and four for the children. Both parents and children responded to each item using a 5-point Likert scale with a response of 1 indicating "I strongly agree" and a response of 5 indicating "I strongly disagree".

(9) Demographic Data was collected when participants first signed up for the workshops.

\section{Data Analysis}

In terms of quantitative data analysis, association between categorical variables was evaluated using Chi squared test or Fisher's exact test. Spearman's correlation coefficient was calculated to estimate the association between ordinal variables. Results are reported as the estimated coefficient and the corresponding $p$-value for the null hypothesis that the correlation coefficient is zero. Paired $t$-test was used to compare pre- and post-workshop scores for a construct.

In terms of qualitative analysis, design journals and websites were analyzed and coded according to the level of complexity displayed by the projects. Interviews and video tapes were partially transcribed and emergent themes were identified. For example, "conceptions about learning", "parent-child interactions as directed by parent, by child or negotiated" "ideas of what it means to work at home on a project", "learning and playing", etc. were some of the emergent themes. Websites were also analyzed and grouped according to emergent categories and level of complexity displayed by the projects.

\section{The Learners: Who Comes to these Workshops?}

As stated earlier, one of the aims of this paper is to understand the kinds of learners that chose to attend these family workshops. One of the premises of Project InterActions is that to educate young children in the realms of technology we also need to provide educational opportunities for their parents. Therefore we need to understand 
Table 3 Adult demographics

\begin{tabular}{|c|c|c|c|}
\hline \multirow[t]{2}{*}{ Gender } & \multirow[t]{2}{*}{$N=40$} & Male & $25(63 \%)$ \\
\hline & & Female & $15(37 \%)$ \\
\hline \multirow[t]{4}{*}{ Education } & \multirow[t]{4}{*}{$N=40$} & High School & $5(13 \%)$ \\
\hline & & $\mathrm{BA}$ & $20(50 \%)$ \\
\hline & & Grad school & $11(27 \%)$ \\
\hline & & $\mathrm{PhD}$ or equivalent & $4(10 \%)$ \\
\hline \multirow[t]{5}{*}{ Ethnicity } & \multirow[t]{5}{*}{$N=39$} & Asian & $3(8 \%)$ \\
\hline & & Latino & $1(3 \%)$ \\
\hline & & Caucasian (white) & $25(66 \%)$ \\
\hline & & African American & $2(5 \%)$ \\
\hline & & Biracial & $7(18 \%)$ \\
\hline \multirow[t]{6}{*}{ Religion } & \multirow[t]{6}{*}{$N=39$} & Atheist/Agnostic & $18(46 \%)$ \\
\hline & & Jewish & $3(8 \%)$ \\
\hline & & Catholic & $9(23 \%)$ \\
\hline & & Muslim & $1(3 \%)$ \\
\hline & & Christian & $4(10 \%)$ \\
\hline & & Other & $4(10 \%)$ \\
\hline $\begin{array}{l}\text { Computer at } \\
\text { home }\end{array}$ & $N=40$ & Yes & $40(100 \%)$ \\
\hline \multirow{5}{*}{$\begin{array}{l}\text { Areas good } \\
\text { at in school }\end{array}$} & \multirow[t]{5}{*}{$N=40$} & Math/Science & $5(13 \%)$ \\
\hline & & Language & $12(30 \%)$ \\
\hline & & Both (math, science & $20(50 \%)$ \\
\hline & & and language) & $3(7 \%)$ \\
\hline & & $\begin{array}{l}\text { Other (music, arts, } \\
\text { sports, etc.) }\end{array}$ & \\
\hline \multirow{4}{*}{$\begin{array}{l}\text { Skills used } \\
\text { in the job }\end{array}$} & \multirow[t]{4}{*}{$N=40$} & Math/Science & $6(15 \%)$ \\
\hline & & Language & $6(15 \%)$ \\
\hline & & $\begin{array}{l}\text { Both (math, science } \\
\text { and language) }\end{array}$ & $24(60 \%)$ \\
\hline & & $\begin{array}{l}\text { Other (music, arts, } \\
\text { sports, etc.) }\end{array}$ & $4(10 \%)$ \\
\hline \multirow{2}{*}{$\begin{array}{l}\text { Previous } \\
\text { parent-child } \\
\text { workshops }\end{array}$} & \multirow[t]{2}{*}{$N=40$} & Yes & $7(17 \%)$ \\
\hline & & No & $33(83 \%)$ \\
\hline
\end{tabular}

who might take advantage of the opportunity to participate in weekend workshops and in which ways. This section of the paper presents results from the study that addresses this issue.

Recruitment was conducted by distributing flyers in all elementary schools in the area and the two lab schools associated with the researcher's university, after asking principals for permission. Information about the Project InterActions workshop was also distributed across several mailing lists for families in the area. The informational flyers had a playful image depicting robots and the following questions: "Are you an adult-child pair that wants to learn something new together? Do you like to build with LEGOs? Do you want to learn how to program a computer?" The text read as follows: "We're inviting 1 st \& 2nd graders \& their parent or guardian to work with Tufts
University students in a series of workshops to learn how to turn their own special LEGO creation into a robot that moves using a computer program called RoboLab. The adult-child pair must commit to EITHER all FIVE Saturday (child only) or all FIVE Sunday workshops (Parentchild)" The workshop had a cost of $\$ 40$ to cover materials and snacks. Several tuition fellowships were available for those interested in coming but with no available means.

Baseline demographic factors of primary interest of parents and children who chose to attend Project InterActions workshops were gender, ethnicity, religion, language spoken at home, educational level of the parents, having a computer at home, curricular areas in which parents and children considered themselves as competent while in school, type of work of the parents (i.e. skills involved as they relate to curricular areas), and previous experience in other parent-child workshops. These demographics are reported separately for adults (see Table 3) and children (see Table 4). Note that all parents answered the questionnaires, regardless of the way in which they chose to participate in the learning experience (by coming together with their children to the workshops or by only working from home).

The studies involved a diverse group in terms of ethnicity, religion and last degree of education achieved. However, more fathers than mothers chose to participate in the workshops, and more boys than girls. Besides, when adults were given the choice of either coming to the workshop with their children or participating from home, there was a significantly higher proportion of fathers who chose to come to the workshops with their children $(68 \%$ of the 25 fathers and $20 \%$ of the 15 mothers, $p<0.01$ ). This result is not surprising due to the technological theme and the use of the word "robotics" in the recruitment brochures. Research suggests that attitudinal gender differences related to physical science and mathematics begin to develop by the earliest elementary school years and that parents perceive boys as more competent in science than girls and that they see jobs related to math or science as more male dominated (Andre et al. 1999). This gender bias is reported in several studies that emphasize the lack of female participation in the engineering industry (Clewell and Campbell 2002). Thus, it is not surprising that a majority of males chose to attend Project InterActions workshops.

The decision to be co-present at the workshop with their children, instead of only participating in the learning experience from home, was not statistically associated with previous experience in other parent/child workshops (15\% of the non-present and $20 \%$ of the co-present participants had previous experience). Participation in the workshop was not associated either with education level of the parent, type of job of the parent, ethnicity or race of the parent. Neither was 
Table 4 Children demographics

\begin{tabular}{llll}
\hline Gender & $N=40$ & $\begin{array}{l}\text { Male } \\
\text { Female }\end{array}$ & $\begin{array}{l}25(63 \%) \\
15(37 \%)\end{array}$ \\
$\begin{array}{c}\text { Areas good } \\
\text { at in school }\end{array}$ & $N=39$ & $\begin{array}{l}\text { Math/Science } \\
\text { Language }\end{array}$ & $1(3 \%)$ \\
& & $\begin{array}{l}\text { Both (math, science } \\
\text { and language) }\end{array}$ & $34(87 \%)$ \\
Favorite subjects & $N=39$ & Math/Science & $18(46 \%)$ \\
at school & & $\begin{array}{l}\text { Language } \\
\text { Both (math, science } \\
\text { and language) }\end{array}$ & $2(5 \%)$ \\
& & $\begin{array}{l}\text { Other (music, arts, } \\
\text { sports, etc.) }\end{array}$ & \\
& &
\end{tabular}

it associated with curricular areas in which both adults and children identified themselves as being good while at school, nor skills currently used by adults in their jobs.

Other interesting data is that, as shown in Table 4, 46\% of the participating young children claimed that their favorite areas of study at school are math and science. But only 3\% declared themselves as being good in math and science. Since the population in this study involved 4- to 7year-old children, this data is both alarming and inspirational. On the one hand, why children of such young age are already experiencing difficulties in math and science? On the other hand, since almost half of the sample stated that math and science are their favorite subjects in school, how can we leverage this natural interest to help them learn better? Future longitudinal design experiments within the Project InterActions research program will evaluate if the robotics curriculum utilized in this project can also promote better understanding of math and science.

\section{Learning About Robotics}

As shown in Table 5, parents and children reported having gained skills in programming and in making a robot. Statistically significant results are more dramatic for children than for parents in all the workshops. But in fact, all learners were able to create a working robotic project. While some of the projects were more complex than others, all displayed some form of motor movement controlled by a programming sequence. All final projects showed that learners had engaged in the exploration of the powerful ideas planned in the curriculum in three areas:

(1) Engineering Design: Brainstorming, design process, problem solving, identification of constraints, material selection, prototyping.

(2) Programming: Motor autonomy vs. remote operation, programming sequence, feedback, inputs and outputs, debugging.
(3) Mechanical building: Stability, friction, wheel and axle, motion.

Few projects displayed sophisticated mechanical knowledge such as the use of levers, joints or gears.

In terms of programming, the most ambitious projects used sensors and variables. Beals and Bers (2006) in their analysis of differences in learning outcomes between Project InterActions workshops in which children were co-present with their parents and workshops in which parents participated only from home, found that the programming and building knowledge of children in the parent-child workshops was actually less than what the children learned in the child-only workshops, even though the projects in the parent-child workshops were more complex than those in the child-only workshop.

Overall, in this study, all parents and all children perceived an increase in their knowledge about programming and robotics after the workshops (see Table 5). However, children felt that they did not learn as much about building with LEGO robotics. This is consistent with the fact that most final projects done by children on their own were not mechanically sophisticated. Most of the children considered themselves accomplished builders with LEGO bricks before coming to the workshop. However, as observed by the facilitators, although many of them were familiar with LEGO materials, most of them did not know the specific pieces or mechanics to build sturdy mobile robotic creatures and were surprised by how difficult it was. They learned that they did not know as much as they thought they knew about building with LEGO materials before coming to the workshop. This result is consistent with facilitator's observations that playing with LEGO materials is not the same as using LEGO materials with an engineering mindset (Staszowski and Bers 2005). Children came to the workshop knowing how to play with LEGO, but left with basic engineering and mechanical knowledge through the robotics materials.

The following excerpt written on the project's website by a 7-year-old boy who provides a good example of the kind of experiences that most children had. "My project name is The Moving Garden. My project just moves forward and backward. It's important to me because I like to plant a lot. It's also important because it brings happiness. I first thought about how I could make a garden and how I could attach the garden to the car. I decided to connect the garden at the back of the car. I did most of the programming at the Curriculum Lab. I needed a lot of help with programming from my mom and the people at the workshop. The hardest thing was keeping the car together. I learned that you should never get frustrated and when something goes wrong always try again”.

Although there was a significant increase in both parent's and child's self perception on competence and 
Table 5 Adults and children perceived knowledge before and after the workshop

\begin{tabular}{lccll}
\hline & $N$ & Mean DIF $^{\mathrm{a}}$ & $\mathrm{SD}$ & $p^{\mathrm{b}}$ \\
\hline Adults & & & & \\
Building with Legos & 37 & -0.05 & 0.66 & 0.6237 \\
Programming & 37 & 0.48 & 0.73 & 0.0002 \\
Making robots & 37 & 0.86 & 1.13 & 0 \\
Children & & & & \\
Building with Legos & 36 & -0.08 & 0.87 & 0.5710 \\
Programming & 37 & 1.67 & 1.45 & 0 \\
Making robots & 37 & 2.54 & 1.04 & 0 \\
\hline
\end{tabular}

Note: ${ }^{a}$ Difference $=$ Score post workshop - score pre workshop. ${ }^{\mathrm{b}}$ Paired $t$-test

confidence, based on comparing pre and post results obtained through the PTD subscales, the change was dramatically higher for children regarding competence (parents mean difference $=0.24 ; p=0.04$; children mean difference $=1.18 p<0.0001)$. Regarding confidence the change was statistically significant only for the children (parent mean difference $=0.14 ; p=0.11$; children mean difference $=0.43 ; p<0.0001)$.

Although all parents learned about programming and building, parent's scores of competence and confidence in their ability to learn new things with and about technology were positively correlated with having a job in the area of information technology (IT) (Spearman correlation coefficient $r=0.39 ; \quad p=0.016, n=37)$, with previous knowledge about programming $(r=0.52 ; p=0.03$; $n=17)$ and with having previous building skills ( $r=0.58$, $p=0.015 ; n=17)$. Qualitative data collected by notes from workshop coordinators, videotaped interactions, and design journals support this finding by showing that parents with non-IT related jobs and no previous computer experience, had all sorts of difficulties that made their full participation in the workshop less successful, from troubleshooting problems while installing the software at home to being unable to develop a final working project.

Most of these parents did not benefit from the resources we provided for them. They were not successful at using the "help" functions in ROBOLAB, at navigating our resource document or simply communicating with the workshop coordinators when problems arose at home. These parents did not belong to a culture of IT to start with, and therefore they were not familiar with the ways in which problem-solving is done within this field: by either delving deep into the problem and the possible solutions or by asking for help. Some of these parents, as observed by the teachers, felt incompetent and therefore did not want to show that they did not know or understand. This was never the case for the children, who despite being in the preoperational concrete cognitive stage, using Piaget's terminology, were not afraid to ask many questions and use the trial-and-error method (Piaget 1971). Given this finding in future iterations of Project InterActions, it will be important to determine the level of technological expertise of the parents before the beginning of the workshops to be able to provide more support to those in need.

In sum, parents with some previous technological experience benefited most from the workshops than parents who were novices. Based on the notes taken by researchers this can also be explained by the fact that parents who were not familiar with the technological world had to work hard to learn the basics and develop a minimal level of competence.

\section{Perceptions on Learning Together: Working and Playing}

Most of the parents reported that the single thing they enjoyed most during the workshop was working together with their children. One mother with a strong IT background shared how happy she was that her child had learned to "deconstruct an action into a sequence of steps" and therefore was able to talk with her about programming. This new connection with her son was very important to her since she was used to expressing herself through programming: "This (workshop) has gotten us started, and I think we will continue together (programming) at home". Other parents also expressed how rewarding it was for them to see their children showing "keen interest in working on a project from an original idea to accomplishing their goals by solving problems and proudly presenting and demonstrating their projects to us".

Other parents felt that their children's presence in the workshop was critical for their own learning, as stated in the final project website by one of the fathers:

The hardest thing was to develop designs that we could then create to make what we wanted. We just never were able to pull the construction off. And while I was disappointed and ready to give up, Peter (the son) never wanted to quit. I learned that he has a great perspective on projects like this and knows that with the right time, parts, and design, we eventually would have been able to create our Toyagumon [ $a$ walking biped].

As gathered through qualitative information, parents expressed two types of concerns regarding their participation in the workshop. Some complained that there was not enough direct instruction and guidance on the part of the workshop facilitators. They were not used to constructionist learning environment and grew up in a time in which learning was more teacher-centric. Others expressed 
that the workshop was too intensive and required big time commitments, both during the weekends and at home.

How did parents and children work at home? Fisher's exact test was used to compare parents' and children's perceptions regarding their way of participating both at home and in the workshop. Children's participation at home was more frequent than parents' participation at home. However, while $40 \%$ of the children said that they worked a lot at home, $38 \%$ of the parents said almost the opposite, that the children mostly never worked at home, $(p=0.0373)$. The same question was asked in different ways in the post questionnaires and informally by the workshop facilitators and the same response was obtained: children tended to say that they worked more than their parents say they did. This difference in perception between parents and children extends to the way in which each group defined their way of working together. While $54 \%$ of the children reported that they often worked at home with their parents, only $16 \%$ of the parents said they did, $(p=0.0038)$. Why this difference in perception? Do children consider playing part of their working, while parents tend to have a more structured view of what working with technology is? Were these parents absent when their children were playing/working, as most of the participating parents were fathers who might or might not be at home after school when children play?

The striking differences between children's and parent's views of "working" suggests that future design experiments will focus on understanding what each of the groups considers working. For example, from data gathered in informal conversations with the workshop participants, it was observed that for many children, playing with the LEGO materials and ROBOLAB, without accomplishing a specific advance in their final project, was considered "working", while for most of the parents this was merely defined as "playing around", but not accomplishing any work.

\section{Discussion}

This paper presented Project InterActions, a series of robotic workshops set up as mutigenerational communities of practice. Three different dimensions of this work were presented. First, the design and implementation of the Project InterActions constructionist workshops, in which families were invited to create their own robotic projects while learning about programming and building. Although the workshops followed a constructionist pedagogy (e.g. learners were encouraged to learn by doing, not by being taught), a curriculum of powerful ideas from the realm of robotics was followed. Second, this paper presented results about what kind of learners chose to participate in these family workshops and in which ways. Understanding more about who are the potentially interested learners (both adults and children) is an important step towards conceiving more wide-reaching interventions of this sort. Third, this paper presented results regarding the learning outcomes, or levels of participation in the Project InterActions community of practice. Results showed that both parents and children were able to learn how to build and program a robot, but most importantly, they felt that they gained confidence and competence regarding technology in general.

This research provides insights into how to develop educational interventions that would educate parents, as well as children, in new domains of knowledge and skills. For example, while it shows the potential of multigenerational communities of practice to encourage learning about technology, it also sheds light on the fact that parents and children learn in different ways and that there are differences amongst parents themselves. For example, previous experience and exposure to IT plays a great role in the kind of learning experience parents can have. Future studies will explore how new iterations of Project InterActions workshops could be designed to address the fact that, as reported in the results, the more skilled parents benefited the most from the workshops. It is our goal to understand what elements need to be nurtured in the CoP so the disadvantaged can excel as well.

Project InterActions also shows the potential of new technologically-rich learning environments that motivate non-traditional learners, such as fathers coming to learn together with their children. Future work might explore why more fathers than mothers chose to participate in the study by coming together with their children to the weekend workshops. Was this choice due to the technological nature of the workshops? Was it influenced by the cultural changes occurring in the US regarding shifting family roles? Was it because fathers were looking for a chance to spend quality time with their children?

As in any other domain of learning in early childhood, parents have an important role in the education of their children. Project InterActions is designed to teach to both parents and children in the context of a constructionist community of practice. While technology-based family workshops present their own challenges, they also bring some long-term benefits in terms of educating parents. First, parents can learn how to model learning by asking questions, managing frustration, and not giving up when things do not work as expected. Second, parents who are technologically-literate can provide helpful assistance for teachers who want to use technology in the classroom, but need more adult hands (this is especially true when working with robotics). Third, parents can begin to reflect about their own learning experiences and might become 
strong advocates for the power of learning with technology in early childhood. These parents can be potential allies for teachers who are seeking systemic educational change and see the computer as an agent of this change.

In sum, findings from Project InterActions have implications for addressing the need to support teachers who want to incorporate technology and engineering into their classrooms but are not confident enough in their skills. This research shows that, using creative ways, parents can become important players in the technological education of their young children and become "stewards of technological change", as mandated by Technically Speaking (Pearson and Young 2002).

Acknowledgements Many people have made this research possible: The students in the DevTech research group and the CEEO (Center for Educational Engineering Outreach) at Tufts University. In particular, I am grateful to Lindsay Groff, Laura Beals, Kevin Staszowski, and Jason Kahn for their hard work on the project. Thanks to Liliana Orellana for her statistical work and to Clement Chau and Laura Beals for thoughtful comments and edits in the manuscripts. Finally, I would like to thank the LEGO group and Chris Rogers for funding this project. Initial funding was also provided by a FRAC award given by Tufts University.

\section{References}

Andre T, Whigham M, Hendrickson M, Chambers S (1999) Competency beliefs, positive affect, and gender stereotypes of elementary students and their parents about science versus other school subjects. J Res in Sci Teach 36(6):719-747

Barab S, Squire K (2004) Design-based research: putting a stake in the ground. J Learn Sci 13(1):1-14, Lawrence Erlbaum, NY

Beals L, Bers M (2006) Robotic technologies: when parents put their learning ahead of their child's. J Interact Learn Res 17(4):341-366

Bell P (2004) On the theoretical breadth of design-based research in education. Educ Psychol 39(4):243-253, Lawrence Erlbaum, NY

Bers M (2004) Parents, children and technology: making robots, exploring cultural heritage and learning together, American Educational Research Association (AERA). Presentation given in April 2004 in LA, CA

Bers M (2006) The role of new technologies to foster positive youth development. Appl Dev Sci 10(4):200-219, Lawrence Erlbaum Associates, Mahwah

Bers M (2007a) From blocks to robots: learning with technology in early childhood. Teacher's College Press

Bers M (2007b) Positive technological development: working with computers, children, and the Internet. MassPsych 51(1):5-7, 18-19

Bers M, Urrea C (2000) Technological prayers: parents and children exploring robotics and values. In Druin A, Hendler $\mathrm{J}$ (eds) Robots for kids: exploring new technologies for learning experiences. Morgan Kaufman, New York, pp 194-217

Bers M, New B, Boudreau L (2004) Teaching and learning when no one is expert: children and parents explore technology. J Early Child Res Pract 6(2)

Bers M, Ponte I, Juelich K, Viera A, Schenker J (2002) Integrating robotics into early childhood education. Child Educ Annual AACE, pp 123-145

Bers M, Portsmore M (2005) Teaching partnerships: early childhood and engineering students teaching math and science through robotics. J Sci Educ Technol 14(1):59-74, Springer, NY
Bredekamp S, Copple C (1997) Developmentally appropriate practice in early childhood programs. National Association for the Education of Young Children

Brown AL (1992) Design experiments: theoretical and methodological challenges in creating complex interventions. J Learn Sci 2:141-178

Cassidy S, Eachus P (2002) Developing the computer user selfefficacy (CUSE) scale: investigating the relationship between computer self-efficacy, gender and experience with computers. J Educ Comput Res 26(2):169-189

Cejka E, Rogers C, Portsmore M (2006) Kindergarten robotics: using robotics to motivate math, science, and engineering literacy in elementary school. Int J Eng Educ 22(4):711-722

Chau C, Bers M (2006) Positive technological development: a systems approach to understanding youth development when using educational technologies. In Barab S, Hay K, D Hickey (eds) Proceedings of the International Conference of the Learning Sciences. LEA Publishing, pp 902-903

Clewell BC, Campbell P (2002) Taking stock: where we've been, where we are, where we're going. J Women Minor Sci Eng 8:255-284

Cobb P, Confrey J, diSessa A, Lehrer R, Schauble L (2003) Design experiments in educational research. Educ Res 32(1):9-13

Committee on Information Technology Literacy (1999) Being fluent with information technology. National Academy Press, Washington

Collins A (1992) Toward a design science of education. In Scanlon E, O'Shea T (eds). New directions in educational technology. Springer-Verlag, Berlin

Cuban L (2001). Oversold and underused. Computers in the classroom. Harvard University Press, Cambridge

DeLuca D (2003) Robotics and teaching: promoting the effective use of technology in education. Unpublished Senior Thesis, Department of Child Development, Tufts University

DiSessa A, Cobb P (2004) Ontological innovation and the role of theory in design experiments. J Learn Sci 13(1):77-103, Lawrence Erlbaum, NY

DiSessa AAHD, Sherin B, Kolpakowski T (1991) Inventing graphing: metarepresentational expertise in children. J Math Behav 10:117-160

Edelson DC (2002) Design research: what we learn when we engage in design. J Learn Sci 11(1):105-121

Erwin BMC, Rogers C (2000) LEGO engineer and RoboLab: teaching engineering with LabVIEW from kindergarten to graduate school. Int J Eng Educ 16(3):181-192

Fishman B, Marx R, Blumenfeld P, Krajcik J, Soloway E (2004) Creating a framework for research on systemic technology innovations. J Learn Sci 13(1):43-76, Lawrence Erlbaum, NY

Hess R, McGarvey L (1987) School-relevant effects of educational uses of microcomputers in kindergarten classrooms and homes. J Educ Comp Res 3(3):269-287

Jordan G, Snow C, Porche M (2000) Project EASE: the effect of a family literacy project on kindergarten students' early literacy skills. Read Res Q 35(4):524-546

Kafai Y, Resnick M (1996) Constructionism in practice. Lawrence Erlbaum Associates

Kahn J, Bers M (2005) An examination of early elementary student's approach to engineering. In: Proceedings of the 2005 American Society for Engineering Education Annual Conference and Exposition. American Society for Engineering Education, Washington, DC

Lave J, Wenger E (1991) Situated learning: legitimate peripheral participation. Cambridge University Press, Cambridge

Lerner R, Lerner JV, Almerigi JB, Theokas C, Phelps E, Gestsdottir S, Naudeau S, Jelicic H, Alberts A, Ma L, Smith LM, Bobek DL, Richman-Raphael D, Simpson I, DiDenti Christiansen E, von Eye A 
(2005) Positive youth development, participation in community youth development programs, and community contributions of fifth-grade adolescents. J Early Adolescence 25(1):17-71

Martin F (2001) Robotic explorations: a hands-on introduction to engineering. Prentice Hall

Papert S (1980) Powerful ideas in mind-size bites. Mindstorms: children, computers, and powerful ideas. Basic Books, NY, pp $135-155$

Papert S (1991) What's the big idea: towards a pedagogy of idea power. IBM Syst J 39:3-4

Papert S (1993) The children's machine: rethinking school in the age of the computer. Basic Books, New York

Pearson G, Young T (eds) (2002). Technically speaking: why all Americans need to know more about technology. National Academy Press, Washington

Piaget J (1971) The theory of stages in cognitive development. In: Green DR (ed) Measurement and Piaget. McGraw, New York, pp 1-11

Portsmore M (1999) ROBOLAB: intuitive robotic programming software to support life long learning, APPLE Learning Technology Review, Spring/Summer 1999

Resnick M (1998) Technologies for lifelong kindergarten. Educ Technol Res Dev 46(4):43-55

Resnick M (2003) Playful Learning and Creative Societies. Education Update 8(6), February 2003

Richardson K (1998) Models of cognitive development. Psychology Press

Rogers C, Portsmore M (2001) Data acquisition in the dorm room: teaching experimentation techniques using LEGO Materials. In: Proceedings of the 2001 American Society of Engineering
Education Annual Conference and Exhibition, Albuquerque, NM. American Society of Engineering Education, Washington, DC

Rogers C, Portsmore M (2004) Bringing engineering to elementary school. J STEM Educ 5(3-4):17-28

Rogoff B (1994) Developing understanding of the idea of communities of learners. Mind Cult Activity 1(4):209-229

Rogoff B, Goodman Turkanis C, Bartlett L (2001) Learning together: children and adults in a school community. Oxford University Press, New York

Senechal M, LeFevre J (2002) Parental involvement in the development of children's reading skill: a five-year longitudinal study. Child Dev 73 (2):445-460

Staszowski K, Bers M (2005) The effects of peer interactions on the development of technological fluency in an early-childhood robotic learning environment. Proceedings of the 2005 American Society for Engineering Education

Teale WH (1984) Reading to young children: its significance for literacy development. In: Goelman H, Oberg A, Smith F (eds) Awakening to literacy (pp. 110-121). Heinemann Educational Books NY, Portsmouth

Turbak F, Berg R (2002) Robotic design studio: exploring the big ideas of engineering in a liberal arts environment. J Sci Educ Technol 11(3):237-253

Turkle S, Papert S (1992) Epistemological pluralism and the revaluation of the concrete. J Math Behav 11(1):3-33

Wenger E (1998) Communities of practice: learning, meaning, and identity. Cambridge University Press, Cambridge

Wright J, Church M (1986) The evolution of an effective homeschool microcomputer connection. Educ Comput 2:67-74 